This is the accepted manuscript of an article published in Journal of Pest Science 89, 837-850 (2016):

Mazzetto, F., Marchetti, E., Amiresmaeili, N. et al.

Drosophila parasitoids in northern Italy and their potential to attack the exotic pest Drosophila suzukii

This version of the article has been accepted for publication, after peer review, and is subject to Springer Nature's AM terms of use, but is not the Version of Record and does not reflect post-acceptance improvements, or any corrections.

The Version of Record is available online at:

https://doi.org/10.1007/s10340-016-0746-7 


\title{
Drosophila parasitoids in northern Italy and their potential to attack the exotic pest Drosophila suzukii
}

Fabio Mazzetto ${ }^{1}$, Elisa Marchetti ${ }^{2}$, Nasim Amiresmaeili ${ }^{3}$, Dario Sacco ${ }^{1}$, Santolo Francati ${ }^{2}$, Costanza Jucker $^{3}$, Maria Luisa Dindo ${ }^{2}$, Daniela Lupi ${ }^{3}$, Luciana Tavella ${ }^{1 *}$

${ }^{1}$ Dipartimento di Scienze Agrarie, Forestali e Alimentari (DISAFA), University of Torino, via Leonardo da Vinci 44, 10095 Grugliasco, TO, Italy; ${ }^{2}$ Dipartimento di Scienze Agrarie (DipSA), University of Bologna, viale Fanin 42, 40127 Bologna, Italy; ${ }^{3}$ Dipartimento di Scienze per gli Alimenti, la Nutrizione, l’Ambiente (DeFENS), University of Milan, via Celoria 2, 20133 Milan, Italy

*Corresponding author: luciana.tavella@unito.it

\begin{abstract}
Drosophila suzukii is an invasive alien pest recently introduced into Europe and North and South America. Several control methods have been tested, and the ability of natural enemies to control this pest has been investigated. This study aimed to identify the main parasitoids of drosophilids in North Italy via field surveys, and to evaluate the ability of some of those species emerged to parasitize $D$. suzukii compared to indigenous $D$. melanogaster. A nine-site survey from July to October 2014 that exposed fruit (banana and blueberry) for 7 and 14 days obtained six parasitoid species, ranked from highest abundance: Leptopilina boulardi, L. heterotoma (Hymenoptera: Figitidae), Pachycrepoideus vindemiae (Hymenoptera: Pteromalidae), Trichopria $\mathrm{cf}$ drosophilae (Hymenoptera: Diapriidae), Asobara tabida (Hymenoptera: Braconidae), and Spalangia erythromera (Hymenoptera: Pteromalidae). The presence and abundance of these species varied greatly among the sites and across the season. The field survey results showed a relationship between parasitoids and indigenous Drosophila communities and a high host competition. The ability of larval parasitoids L. boulardi and L. heterotoma and pupal parasitoid T. cf. drosophilae to parasitize the exotic and indigenous hosts was laboratory tested. Both larval parasitoids failed to develop on $D$. suzukii, but high mortality was recorded in larvae exposed to L. heterotoma. On the contrary, $T$. cf. drosophilae developed successfully on $D$. suzukii, with no significant differences between the exotic and indigenous hosts. These results beg further investigations of indigenous enemies, particularly $T$. cf. drosophilae, for effective biological control of $D$. suzukii.
\end{abstract}


Key words: spotted wing drosophila, fruit dish traps, no-choice and choice tests, Leptopilina boulardi, Leptopilina heterotoma, Trichopria $\mathrm{cf}$. drosophilae

\section{Key message (80 words)}

- Knowledge of the distribution and abundance of parasitoid species related to frugivorous Drosophilidae is key to implementation of a biological control against Drosophila suzukii.

- Six parasitoid species (three larval and three pupal parasitoids) related to frugivorous Drosophilidae were detected in North Italy.

- Laboratory experiments demonstrated the capability of Trichopria cf. drosophilae to parasitize successfully D. suzukii.

- Rearing and release of parasitoids, such as T. cf. drosophilae, could be implemented for effective control of the exotic fly.

\section{Introduction}

Drosophila suzukii Matsumura (Diptera: Drosophilidae), commonly known as the spotted-wing drosophila, is a pest native to Southeast Asia that is now widespread in other parts of Asia, as well as in North America, South America, and Europe (Kanzawa 1939; Hauser 2011; Calabria et al. 2012; Deprà et al. 2014). Unlike many drosophilids, D. suzukii females can lay eggs in ripening fruits pre-harvest and cause heavy economic losses, especially to cherries and soft fruits as reported in the United States and Europe (Goodhue et al. 2011; Escudero Colomar et al. 2012; Grassi and Pallaoro 2012; Weydert et al. 2012; De Ros et al. 2013). Besides fruit crops, D. suzukii can infest ornamental and wild, alien or native, fruiting plants (including mulberry and fig trees), which can serve as fly reservoirs (Mitsui et al. 2010; Yu et al. 2013; Poyet et al. 2014).

Due to its negative impact on several cropping systems, different control methods have been tested and implemented. Many studies have been directed at finding specific and selective attractants or chemical lures of D. suzukii (Landolt et al. 2012a, b; Cha et al. 2012, 2013, 2014, 2015; Iglesias et al. 2014). Although different substances have shown an attractive effect to $D$. suzukii, they have not yet represented a complete solution for most cropping systems (Rossi Stacconi et al. 2015). While spinosyn, pyrethroid, and organophosphate insecticides effectively control $D$. suzukii in both laboratory and field trials (Bruck et al. 2011), the rapid growth of fly populations and damage occurrences near harvest time require several chemical interventions on fruit at the ripening stage that impact human and environment health negatively. In fact, these treatments raise several risks: residue on fruit, insect resistance, and detrimental effects on pollinators and other beneficial species (Cini et al. 2012; Rota Stabelli et al. 2013). Moreover, research has focused on natural enemies, 
predators and parasitoids, to identify the most promising candidates for an effective biological control, which is an important component of D. suzukii areawide management.

Field surveys and laboratory experiments on potential enemies of $D$. suzukii have been conducted in Japan, North America, and Europe. In central Japan, Asobara japonica Belokobylskij

(Hymenoptera: Braconidae) and Ganaspis xanthopoda (Ashmead) (Hymenoptera: Figitidae) are two common larval parasitoids of frugivorous drosophilids. However, in laboratory trials only $A$. japonica successfully parasitized D. suzukii larvae, whereas G. xanthopoda rarely, if ever, oviposited in these larvae (Mitsui and Kimura 2010). Similarly, in laboratory experiments conducted in France $A$. japonica caused the highest level of parasitism (more than 95\%) in $D$. suzukii larvae (Chabert et al. 2012). Indeed, A. japonica and other species or populations of the genus Ganaspis, native to Southeast Asia as D. suzukii, are considered the most effective larval parasitoids to control the pest (Kacsoh and Schlenke 2012; Kasuya et al. 2013). By contrast, Asobara tabida Nees, which is the most common parasitoid of frugivorous drosophilids in Europe, and $A$. rufescens Foerster have shown no ability to parasitize D. suzukii (Chabert et al. 2012; Cini et al. 2012).

Two larval parasitoids Leptopilina boulardi (Barbotin, Carton \& Kelner-Pillault) and L. heterotoma (Thomson) (Hymenoptera: Figitidae), spread across Europe (Fleury et al. 2004), have been studied in both Europe and the US (Chabert et al. 2012; Kacsoh and Schlenke 2012; Rossi Stacconi et al. 2015). In French and US studies, these parasitoids successfully oviposited in, and killed D. suzukii larvae, yet no adults emerged from the attacked larvae. This finding suggests that they could not develop on this fly, probably because of a strong immune response (Chabert et al. 2012; Kacsoh and Schlenke 2012). However, recently an Italian population of $L$. heterotoma proved to overcome the immunological response of D. suzukii (Rossi Stacconi et al. 2015), promoting further investigation into the capability of these larval parasitoids to parasitize successfully the exotic fly. Under laboratory conditions, pupal parasitoids, such as Pachycrepoideus vindemiae (Rondani) (Hymenoptera: Pteromalidae) and Trichopria cf. drosophilae (Perkins) (Hymenoptera: Diapriidae), proved to be more effective than larval parasitoids (Chabert et al. 2012; Rossi Stacconi et al. 2013). The term "cf." used in the taxonomy of this species is the abbreviation of the latin word "confer" (=compare) indicating the uncertain identification of the species. Pachycrepoideus vindemiae, which is widespread in Europe, the US, and Japan (Mitsui et al. 2007; Rossi Stacconi et al. 2013), is known to parasitize a wide range of hosts, especially cyclorrhaphous Diptera. It can also act as a hyperparasitoid by attacking beneficial Hymenoptera, including A. tabida and L. heterotoma (Van Alphen and Thunissenn 1993; Wang and Messing 2004). Trichopria cf. drosophilae is yet another parasitoid with the capability to develop on various drosophilids, albeit to a lesser degree than $P$. 
vindemiae, including many frugivorous Drosophila species (Mitsui et al. 2007; Chabert et al. 2012; Rossi Stacconi et al. 2015).

Field surveys on parasitoids of frugivorous Drosophilidae have been conducted across the globe (Jansen et al. 1987; Kraaijeveld and Godfrey 1999; Allemand et al. 2002; Mitsui et al. 2007). Most of the studies focused on evaluation of parasitoid resistance and virulence toward indigenous Drosophilidae (Kraaijeveld and Godfrey 1999; Fleury et al. 2009). In Italy, the drosophilidparasitoid community has been studied far less until the recent flurry of work to identify potential parasitoids of the exotic D. suzukii in Northeast Italy after its introduction (Rossi Stacconi et al. 2013, 2015). Therefore, this study aimed first to assess the presence and abundance of indigenous parasitoids of Drosophila spp. in three regions of North Italy (Piedmont, Lombardy, and Emilia Romagna), where D. suzukii has become a noxious crop pest (Gargani et al. 2013; Mazzetto et al. 2015). Second, we selected and tested some parasitoid species emerged from the field-collected samples on exotic host D. suzukii and indigenous host D. melanogaster Meigen in the laboratory, to evaluate their potential as biological control agents of the exotic fly.

\section{Materials and methods}

\section{Field monitoring of parasitoids of Drosophila spp.}

Surveyed sites. Field surveys were carried out in nine total sites (Site) during 2014; three sites were located in each of three North Italy regions (Locality): Piedmont, Lombardy and Emilia Romagna. Following are the fruiting plants (and sites) selected within each region: two blueberry (Boves and Paesana) and one raspberry plantation (Peveragno) in Piedmont; two raspberry (Arcagna and Minoprio) and one blueberry plantation (Minoprio) in Lombardy; one cherry orchard (Cadriano), one uncultivated area with mulberries (Morus sp.) (Dodici Morelli), and one experimental garden with blueberry bushes and fruit trees (cherry, fig, and peach) on the University campus (Bologna) in Emilia Romagna. Locations and characteristics of the surveyed sites are given in Table 1.

The population levels of $D$. suzukii at each site were evaluated by placing a trap baited with $250 \mathrm{~mL}$ of apple cider vinegar (ACV) (5\% acidity). The traps were replaced weekly throughout the trial period (July to October). Removed traps were taken to the laboratory, where the ACV was filtered with a funnel (diameter $26 \mathrm{~cm}$ ) lined with a fine mesh net to retain all insects. Using a brush, all of the Drosophilidae were counted, collected, and preserved in glass tubes $(8 \times 60 \mathrm{~mm})$ filled with $70 \%(v / v)$ ethanol. Finally, with a stereomicroscope and identification key (Vlach 2010), all $D$. suzukii flies were separated from the other Drosophilidae, and the numbers of male and female $D$. suzukii were recorded. 
Field collection and laboratory observation of parasitoids. The presence and abundance of the parasitoids of Drosophila spp. were assessed following a modified protocol used by Fleury et al. (2004). Two open traps (Block) were placed in three different positions along the diagonal of each site from July to October 2014. The open traps consisted of a delta trap, on the bottom of which were placed two plastic dishes (diameter $90 \mathrm{~mm}$ ), one with split banana and one with healthy blueberries (Fruit). Split banana was chosen because it was largely used in similar studies (Novković et al. 2012; Fleury et al. 2004; Chabert et al. 2012), while blueberries were chosen both as a favourite host of $D$. suzukii (Kinjo et al. 2013; Mazzetto et al. 2015) and because they were already used to capture parasitoids (Rossi Stacconi et al. 2013). Each dish represented a statistical unit. To allow oviposition of both larval and pupal parasitoids, the dishes were exposed to natural field colonization for 7 or 14 days. The fruit in six of the dishes was changed every 7 days and the fruit in the other six dishes was changed every 14 days. Overall, four treatments, each with three repetitions, were compared in each site: 1) dishes with banana exposed for 7 days; 2) dishes with blueberries exposed for 7 days; 3) dishes with banana exposed for 14 days; 4) dishes with blueberries exposed for 14 days.

After field exposure, the dishes were transferred to the laboratory, where they were arranged to allow the adult emergence of Drosophila spp. and parasitoids. The fruits from each dish were placed in disposable, net-covered cups (height $76 \mathrm{~mm}$, diameter $60 \mathrm{~mm}$, volume $100 \mathrm{~mL}$ ). The disposable cups were kept at room temperature (about $25^{\circ} \mathrm{C}$ ) for 40 days (i.e., the period necessary to obtain parasitoid emergence) and checked every $48 \mathrm{~h}$ to observe adult emergence. All Drosophila spp. adults were removed, but only the adults emerged in the first 10 days were counted and stored in $70 \%$ (v/v) ethanol inside micro tubes (length $44 \mathrm{~mm}$, diameter $10.8 \mathrm{~mm}$, volume $2 \mathrm{~mL}$ ) to avoid overlapping generations. Next, they were examined to separate individuals of $D$. suzukii from those of other Drosophila species. All parasitoid adults were removed, counted, and stored in $70 \%$ (v/v) ethanol inside micro tubes (length $44 \mathrm{~mm}$, diameter $10.8 \mathrm{~mm}$, volume $2 \mathrm{~mL}$ ) throughout the 40-day period. The adults were then examined, separated, and identified using specific keys (Bouček 1963; Graham 1969; Forshage and Nordlander 2008; Vlach 2010). Some individuals of each species of the different areas were sent to the respective specialist to assure a correct specific identification.

\section{Laboratory evaluation of parasitoid ability to parasitize $D$. suzukii}

Insect rearing. Laboratory trials were carried out to evaluate the ability of local populations of $L$. boulardi, L. heterotoma, and T. cf. drosophilae to parasitize D. suzukii compared to that of $D$. melanogaster; these trials necessitated mass rearing of the five species in our laboratories. Instead, $P$. vindemiae was not tested because its capability to parasitize $D$. suzukii has been widely documented (Chabert et al. 2012; Rossi Stacconi et al. 2013, 2015). 
The colony of $D$. suzukii was started from individuals emerged from blueberries, raspberries, and blackberries collected in Cuneo and Torino provinces in Piedmont (NW Italy) during the summers of 2013 and 2014, and the colony of D. melanogaster was started from individuals obtained in 2013 from the laboratory of G. Gargiulo (University of Bologna, Dipartimento di Farmacia e Biotecnologie). Both colonies were reared on a maize flour-based artificial diet in plastic cylinders (height $6 \mathrm{~cm}$, diameter $3 \mathrm{~cm}$ ) with mesh-covered lids. The larvae were reared on an artificial diet containing $15 \mathrm{~g} \mathrm{~L}^{-1}$ sucrose, $10 \mathrm{~g} \mathrm{~L}^{-1}$ soy flour, $17 \mathrm{~g} \mathrm{~L}^{-1}$ dead yeast, $71 \mathrm{~g} \mathrm{~L}^{-1}$ maize flour, and $5.6 \mathrm{~g} \mathrm{~L}^{-1}$ agar. The diet was supplemented with propionic acid (4.7\%) and a vitamin mixture (2.5\%). Adult flies were kept in Plexiglas ${ }^{\circledR}$ cages $(20 \times 20 \times 20 \mathrm{~cm})$ and fed via cotton balls soaked in a honey and water solution (20\% honey). Twice a week, adults were inserted into three cylinders containing $15 \mathrm{~mL}$ of the diet, and maintained for 2-3 days to obtain oviposition. Upon removal, the cylinders were closed with lids and transferred to a tray.

The colonies of L. boulardi and L. heterotoma were started from individuals emerged from additional dishes with banana and blueberries, placed in the Paesana and Peveragno sites during late summer 2014. The parasitoids were maintained on fruits infested by Drosophila spp. larvae inside Plexiglas ${ }^{\circledR}$ cages $(20 \times 20 \times 30 \mathrm{~cm})$ closed at the top by a fine mesh net $\left(<1 \mathrm{~mm}^{2}\right.$ mesh size $)$, and fed with honey drops placed on small pieces of paper.

The colony of $T$. cf. drosophilae was started from individuals emerged from samples collected at multiple locations in Lombardy in 2014. Newly-emerged parasitoid adults were kept in plastic cylinders (height $6 \mathrm{~cm}$, diameter $3 \mathrm{~cm}$ ) with mesh-covered lids, and fed with honey drops placed on small pieces of paper. Twice a week, about 50 1-day-old D. melanogaster pupae were placed in a cylinder. Eight to ten couples of 2-3-day-old T. cf. drosophilae adults were transferred into the cylinder and removed after $48 \mathrm{~h}$ (Romani et al. 2002).

All insect rearing was maintained at $25^{\circ} \mathrm{C} \pm 1^{\circ} \mathrm{C}, 50-60 \% \mathrm{RH}$ and $16 \mathrm{~L}: 8 \mathrm{D}$ photoperiod.

Laboratory tests with L. boulardi and L. heterotoma. To evaluate the parasitism ability of these two larval parasitoids, no-choice tests were carried out using D. suzukii or D. melanogaster $2^{\text {nd }}-3^{\text {rd }}$-instar larvae, as reported in Fleury et al. (2000). In the tests, 10 larvae of D. suzukii or D. melanogaster were inserted into a plastic dish (height $2 \mathrm{~cm}$, diameter $5.5 \mathrm{~cm}$ ) filled with a thin layer of the artificial diet described above. Similarly to Campan et al. (2002), 5-7-day-old L. boulardi or L. heterotoma females were used. A female, previously kept with a male for $48 \mathrm{~h}$ to allow mating, was introduced into each plastic dish. After $48 \mathrm{~h}$, the female was removed, and the dishes where the female was kept were checked every $48 \mathrm{~h}$ to detect parasitoid or drosophilid adult emergence. For each parasitoid species and each Drosophila species, at least eight replicates were performed, each consisting of 10 larvae (=10 D. suzukii or 10 D. melanogaster exposed to parasitoid). Moreover, 10 
replicates only with $D$. suzukii (each with 10 larvae) and only with $D$. melanogaster (each with 10 larvae) were performed as control without parasitoid. The results were evaluated by number of successfully parasitized larvae (i.e., larvae from which a parasitoid adult emerged), and number of dead larvae (i.e., larvae from which neither a parasitoid nor a drosophilid adult emerged). The tests were conducted at $25^{\circ} \mathrm{C} \pm 1^{\circ} \mathrm{C}, 50-60 \% \mathrm{RH}$ and $16 \mathrm{~L}: 8 \mathrm{D}$ photoperiod.

Laboratory tests with $T$. cf. drosophilae. To evaluate the effectiveness of $T$. cf. drosophilae, nochoice and choice tests were carried out. In both tests, 1-day-old drosophilid pupae were exposed to 2-3-day-old parasitoid females for $48 \mathrm{~h}$, as reported in Romani et al. (2002). The tests were performed in cylinders like those described above, although in this case the bottoms had been previously filled with $15 \mathrm{~mL}$ agar-water suspension (6\% agar) to avoid pupa dehydration. Prior to the experiment, the females were kept with males for at least $48 \mathrm{~h}$ to allow mating. When the females were removed, the cylinders where the females were alive were checked daily to detect parasitoid or drosophilid adult emergence. The pupal weights of the two Drosophila species were compared, and newly-formed pupae $(<24 \mathrm{~h})$ were weighed. Six replicates, each consisting of 10 pupae per species, were tested at $25^{\circ} \mathrm{C} \pm 1^{\circ} \mathrm{C}, 50-60 \% \mathrm{RH}$ and $16 \mathrm{~L}: 8 \mathrm{D}$ photoperiod. For no-choice tests, 10 pupae of $D$. suzukii or D. melanogaster were exposed to one $T$. cf. drosophilae female. For each host species, 10 pupae were not exposed to parasitoid females to be maintained as controls. Six replicates were performed, each consisting of 40 pupae (=10 D. suzukii or 10 D. melanogaster exposed to parasitoids, 10 D. suzukii or 10 D. melanogaster maintained as controls). The results were evaluated with three measures: number of successfully parasitized pupae (i.e., pupae from which a parasitoid adult emerged); number of dead pupae (i.e., pupae from which neither a parasitoid nor a drosophilid adult emerged); development time (days), calculated as the period from pupa exposure to parasitoid females until parasitoid adult emergence.

For choice tests, five pupae of $D$. suzukii and five pupae of D. melanogaster were exposed simultaneously to one $T$. cf. drosophilae female in a cylinder. Each replicate consisted of one cylinder, each containing 10 total pupae (i.e., five pupae per species). After exposure, the pupae of the two species were separated into different cylinders. Twelve replicates were performed and the results were evaluated by the number of successfully parasitized pupae, and number of dead pupae, calculated as previously described.

\section{Statistical analyses}

Field data were separated into two different datasets. The first set included data obtained from fruit exposed for both 7 and 14 days that was removed on the same date (i.e., every 14 days), where Exposure equaled 7-14 days (Dataset 7-14 days). The second set included all data obtained from the 
fruit exposed for 7 days and was removed weekly, where Exposure was equal to 7 days (Dataset 7 days).

The emerged adults of each parasitoid species were pooled over the season for each dish and analyzed through a Generalized linear mixed effect model procedure with a Poisson distribution and $\log$ link. Locality, Fruit, Exposure, and their two-way interactions were considered as fixed effects; Site (Locality) [Site as a nested variable in Locality], Block (Site), and the interactions Fruit*Site (Locality) and Exposure*Site (Locality) were considered as random effects. When fixed effects were found to be significant, means were separated through the sequential Bonferroni post hoc test. In laboratory tests, the number of emerged parasitoids and number of dead host individuals were analyzed for each parasitoid species through a Generalized linear model with a binomial distribution and a logit link. Host and eventually presence/absence of parasitoid and their interaction were considered as fixed effects. When effects were shown to be significant, means were separated through the Bonferroni post hoc test.

The pupal weight of $D$. suzukii and D. melanogaster and the development time of $T$. cf. drosophilae in the two host species were analyzed by the Student's t-test for independent samples. Data were transformed by square root to achieve homogeneity of variance (Levene test) and normality (Shapiro-Wilk test).

Statistical analyses were performed through SPSS Statistics 22 (IBM Corp. Released 2013, Armonk, NY).

\section{Results}

\section{Field monitoring of parasitoids of Drosophila spp.}

Field monitoring by traps baited with ACV confirmed the presence and abundance of D. suzukii in all surveyed sites. Despite the capture of large numbers of the exotic fly in ACV traps, relatively few (below 5.0\%) D. suzukii, as compared to other Drosophila spp., emerged from the fieldexposed fruit dishes (Table 2). Six parasitoid species were obtained from the field-exposed fruit dishes: L. boulardi, L. heterotoma, A. tabida, P. vindemiae, T. cf. drosophilae, and Spalangia erythromera Forster (Hymenoptera: Pteromalidae) (Table 2). The presence and abundance of these species varied greatly by site; only $L$. boulardi and $P$. vindemiae emerged from fruit dishes exposed in all sites, while all six species were found only in Minoprio in Lombardy (Table 2). Overall, $L$. boulardi, L. heterotoma, $P$. vindemiae, and $T$. cf. drosophilae were more common and generally found during field monitoring. On the contrary, A. tabida and S. erythromera were found occasionally and in fewer numbers in Piedmont and Lombardy (Table 2). 
Among the six species, the larval parasitoid L. boulardi was the most abundant (Table 2). Adults emerged 15-25 days after fruit dish removal, and in all surveyed sites the presence of $L$. boulardi was recorded from July to October (Figure 1A). Aside from abundance, differences were found among the regions and across the season. The highest level of parasitism was recorded in Piedmont in late September (weeks 38-39: 1,341 wasps). A similar trend was observed in Lombardy during the summer, although the highest level of parasitism occurred two weeks later than in Piedmont (weeks 40-41: 742 wasps). In Emilia Romagna, fewer L. boulardi were collected overall, and the peak of parasitism occurred earlier (weeks 36-37 and weeks 38-39: 274 wasps) (Figure 1A). Statistical analysis of Dataset 7-14 days showed that the presence and abundance of $L$. boulardi were significantly affected by Fruit used in the dishes, interval of Exposure, Locality*Fruit, Locality*Exposure, and Exposure*Fruit (Tables 3, 4). In general, significantly more adults emerged from dishes with banana exposed for 7 days, while no significant differences were found among the Localities. Similarly, analysis of Dataset 7 days confirmed the significant effect of Fruit and Locality*Fruit on the number of L. boulardi, principally based on Emilia Romagna data (Tables 5, 6). Aside from Blocks, random effects did not introduce variability into the results for either $L$. boulardi or other species.

Based on the total number of emerged adults, the second most common parasitoid was $L$. heterotoma (Table 2). Even though this larval parasitoid was particularly abundant in Piedmont, especially in Peveragno, it was absent in Emilia Romagna (Table 2). Like L. boulardi, adults emerged 15-25 days after fruit dish removal following field exposure during July to October. In Piedmont, the highest level of parasitism was observed in mid-August (weeks 34-35: 1,184 wasps) and remained high throughout September, followed by a drastic decrease in October $(<100$ wasps) (Figure 1B). Leptopilina heterotoma was also recorded in Lombardy throughout the survey period except during the first two weeks (28-29), although specimen numbers were considerably below those in Piedmont. Indeed, fewer than 100 adults in total emerged from fruits with the highest number obtained during August (weeks 34-35: 70 wasps) (Figure 1B). Despite the high variability in distribution and relative abundance of L. heterotoma among the Localities, statistical analysis detected no significant differences except for the Exposure*Fruit interaction, indicating a significant preference for dishes with banana exposed for 7 days where the parasitoid was found (Tables 3, 4). The species that ranked third in abundance was pupal parasitoid $P$. vindemiae (Table 2). In this instance, adults emerged, albeit in variable amounts, 20-30 days after fruit dish removal following field exposure in all sites from mid-July to October. This pupal parasitoid was most abundant in Lombardy, especially in Arcagna (Table 2). In this region, two main peaks of emergence were observed from fruits exposed during July (weeks 30-31: 357 wasps) and late summer (weeks 36-37: 
572 wasps). Thereafter, the number of parasitoids decreased to fewer than 30 wasps in October (Figure 1C). In Piedmont, larger numbers of $P$. vindemiae were found in the latter halves of both August (weeks 34-35: 228 wasps) and September (weeks 38-39: 236 wasps) (Figure 1C). On the contrary, the highest number of $P$. vindemiae was observed in Emilia Romagna in late October (weeks 42-43: 180 wasps), while emergence during the summer was lower than that of the other regions (Figure 1C). Statistical analysis of Dataset 7-14 days demonstrated that the presence and abundance of $P$. vindemiae were significantly affected by Fruit, interval of Exposure, Locality*Exposure, Exposure*Fruit (Tables 3, 4). Overall, significantly higher numbers of adults emerged from dishes with banana exposed for 14 days. By contrast, no significant effects were found during analysis of Data set 7 days (Table 5, 6).

The pupal parasitoid T. cf. drosophilae was recorded in Lombardy and in Emilia Romagna, but it was never found in Piedmont (Table 2). When observed, its adults generally emerged 18-22 days after fruit dish removal. In Lombardy, where its numbers were fewer than $P$. vindemiae, this pupal parasitoid was consistently collected from July to October, reaching the highest level in September (weeks 36-37: 41 wasps) (Figure 1D). In Emilia Romagna, T. cf. drosophilae emerged only from fruits exposed from mid-August to mid-September (weeks 34-35: 45 wasps) except for two specimens that emerged one each at the beginning and end of the survey (Figure 1D). Statistical analysis of both datasets resulted in no significant effects of Locality, Fruit, or interval of Exposure on the numbers of $T$. cf. drosophilae except for Locality*Fruit during analysis of Dataset 7 days (Tables 3, 4, 5, 6).

The remaining two species, $A$. tabida and $S$. erythromera, were only occasionally found in Piedmont and Lombardy. In Piedmont in particular, five specimens of $A$. tabida emerged during the season as opposed to the 76 specimens that emerged in Lombardy, especially from fruits exposed during September and October (Table 2). Twenty-three and seven specimens of pupal parasitoid $S$. erythromera were detected throughout the season in Piedmont and Lombardy, respectively.

\section{Laboratory evaluation of parasitoid ability to parasitize $D$. suzukii}

In the laboratory, all the tested species proved to parasitize successfully D. melanogaster, whereas only $T$. cf. drosophilae was able to parasitize successfully $D$. suzukii and no significant differences in parasitism rates were found between the two hosts (Table 7). Trichopria cf. drosophilae took significantly longer to develop in D. suzukii (19.3 \pm 0.5 days) than in D. melanogaster $(17.8 \pm 0.9$ days) (t-test for independent samples, $\mathrm{t}=13.282, \mathrm{df}=1,98, \mathrm{P}<0.001$ ). Conversely, L. boulardi and $L$. heterotoma failed to parasitize $D$. suzukii, which produced significantly different parasitism rates between the native and exotic hosts (GLM, L. boulardi: $\chi^{2}=171.429, \mathrm{df}=1, \mathrm{P}<0.001$; L. heterotoma: 
$\left.\chi^{2}=126.452, \mathrm{df}=1, \mathrm{P}<0.001\right)$ (Table 7). These findings caused two-choice tests to be performed with T. cf. drosophilae alone.

Dead fly comparison (i.e., larvae or pupae from which no adults of either flies or parasitoids emerged) yielded quite varied results by parasitoid species. In tests with $L$. boulardi, the mean number of dead flies was significantly higher in D. melanogaster than in D. suzukii (GLM, $\left.\chi^{2}=15.375, \mathrm{df}=1, \mathrm{P}<0.001\right)$. Nevertheless, no significances were found in the interaction between host and presence/absence of parasitoid or in the mean number of dead flies in the presence or absence of parasitoid (Table 7). By contrast, in tests with L. heterotoma, significant differences resulted between tests in presence or absence of parasitoid; specifically, a higher mortality was detected in the presence of the parasitoid $\left(\mathrm{GLM}, \chi^{2}=5.815, \mathrm{df}=1, \mathrm{P}=0.016\right)$. In particular, the mean number of dead D. suzukii was significantly higher in tests with L. heterotoma than in the control, which showed that this species affected exotic fly mortality $\left(\mathrm{GLM}, \chi^{2}=10.392, \mathrm{df}=1, \mathrm{P}=0.001\right)$ (Table 7). Finally, in tests with $T$. cf. drosophilae, the mean number of dead flies was significantly higher in both $D$. melanogaster versus $D$. suzukii (GLM, $\left.\chi^{2}=4.531, \mathrm{df}=1, \mathrm{P}=0.033\right)$ and in the presence of parasitoid versus the control $\left(\mathrm{GLM}, \chi^{2}=4.531, \mathrm{df}=1, \mathrm{P}=0.033\right)$. The interaction between host and presence/absence of parasitoid was not significant (Table 7).

In two-choice tests, $T$. cf. drosophilae showed it could attack and parasitize successfully both $D$. suzukii and D. melanogaster, with no significant differences noted between the native and exotic hosts. Instead, higher pupal mortality occurred in D. melanogaster versus D. suzukii (GLM, $\chi^{2}=5.687, \mathrm{df}=1, \mathrm{P}=0.017$ ) (Table 7). Additionally, the mean weight of the newly-formed $D$. suzukii pupae was significantly above that of $D$. melanogaster pupae $(2.39 \pm 0.15 \mathrm{vs} .1 .04 \pm 0.07 \mathrm{mg})$ (t-test for independent samples, $\mathrm{t}=268.70, \mathrm{df}=1,118, \mathrm{P}<0.001$ ).

\section{Discussion}

Our research demonstrated the presence of six parasitoid species related to frugivorous Drosophilidae in North Italy, and identification among these species of a potential candidate to control exotic fly D. suzukii. Overall, the survey revealed the high variability in the abundance and population trend of each parasitoid species not only among the three localities, but also across sites within a locality. This variability likely related to survey site characteristic differences, and consequently, to the trend in Drosophilidae population levels. Different types of trees, bushes, and shrubs, such as mulberries, blueberries, cherry, peach and fig trees, most of which are favourite hosts of $D$. suzukii, in the sites in Emilia Romagna may have provided supplementary or alternative food for Drosophila spp. throughout the season, which would account for the lower fly numbers that emerged from fruits exposed in this locality. As would be expected, these lower Drosophilidae 
numbers mirrored lower amounts of parasitoids emerged from fruits exposed there. The influence of surrounding vegetation on Drosophilidae attraction was also evident from the opposite perspective, that is, when high numbers of other drosophilids were captured in ACV traps. In Piedmont and Lombardy, where monitoring was conducted in blueberry and raspberry plantations with limited presence of other host plants (especially after the harvest), it made the fruits exposed in the field more attractive to drosophilids. The influence of the site on Drosophila spp. abundance and composition has been already demonstrated; for example, Ferreira and Tidon (2005) showed that Drosophilidae populations varied according to the level of urbanization. In all surveyed sites, D. suzukii was always present as determined by ACV traps. However, the highly variable rate of trap capture of the exotic flies in comparison with other Drosophilidae highlighted the scarce selectivity of ACV as others have previously observed (Landolt et al. 2012b; Cha et al. 2014; Iglesias et al. 2014; Burrack et al. 2015). Despite its high presence, very few adults of the exotic fly emerged from the field-exposed fruits, probably due to competition for food between $D$. suzukii and native drosophilids. Although the competition between D. suzukii and other drosophilids has not yet been investigated, studies of food competition have been conducted in a number of congeneric species (Montchamp-Moreau 1983; Fleury et al. 2004). Consequent to the low number of D. suzukii, most parasitoids found in our survey emerged from native drosophilids (more than 80,000), which were not identified because our study was aimed at detecting the parasitoids and evaluating their potential as biological control agents of D. suzukii. However, these data could provide useful information on communities of frugivorous drosophilids and their interactions with natural enemies, not yet investigated in our regions and worthy of further studies. Nonetheless, our results have broadened the knowledge on the distribution and abundance of parasitoid species in North Italy, and may represent important achievements in the implementation of biological control strategies against D. suzukii.

Among the six parasitoid species obtained, A. tabida and S. erythromera were only occasionally recorded in North Italy. The relationships of Asobara spp. with their hosts have been studied in other countries, especially in Japan (Mitsui et al. 2007; Mitsui and Kimura 2010; Novković et al. 2012; Kohyama and Kimura 2015; Nomano et al. 2015). High levels of competition with other parasitoids, host unsuitability and egg encapsulation in A. tabida may be the principle reason for its scarcity in our study localities. The four other species were more abundant in almost all surveyed sites, which showed that they likely play a role in drosophilid population regulation.

The presence of larval parasitoids L. boulardi and L. heterotoma, generally observed in Europe (Kraaijeveld and Van Alphen 1994; Fleury et al. 2004, 2009; Moiroux et al. 2013), was confirmed in North Italy from our findings. Our survey also revealed their highly variable distribution by 
locality; in fact, only L. boulardi was found in all sites while L. heterotoma was never collected in Emilia Romagna. As noted above, lower numbers of larval parasitoids reflect lower numbers of Drosophilidae emerged from fruits, but this explanation fails to fully account for the complete absence of L. heterotoma in Emilia Romagna. The role of competition might provide some hints as it has been studied thoroughly in drosophilid parasitoids (Vet and van Opzeeland 1985; Fleury et al. 2000; Fleury et al. 2009). Similarly, different resources and environmental factors have been shown to affect the coexistence of $L$. boulardi and L. heterotoma. Of these two species, the second has been considered more generalist - and therefore, a better competitor - than the first because it can exploit alternative host species (Fleury et al. 2004). However, in a survey conducted in Tunisia $L$. boulardi proved to be a better competitor than L. heterotoma (Carton et al. 1991). A similar competition could explain the variability in presence and abundance observed in our survey. Here, both species emerged mainly from fruit exposed for 7 days, in which higher numbers of Drosophilidae larvae suitable for their parasitism were expected. Moreover, they showed a preference for banana over blueberries, which might derive from the fact that the highest number of Drosophilidae emerged from banana (data not shown). Banana traps to capture Leptopilina spp. have already been largely adopted (Chabert et al. 2012; Moiroux et al. 2013; Marchiori et al. 2015) because of the strong preference of Drosophila spp. to oviposit on fermented banana (Markow and O’Grady 2006).

In laboratory tests, our populations of L. boulardi and L. heterotoma proved they were unable to develop on the exotic fly, which aligns with observations in other studies in Europe and North America (Chabert et al. 2012; Poyet et al. 2013). Therefore, the population of L. heterotoma collected in Northeast Italy may represent the only known case to date that demonstrates the ability of this parasitoid to overcome the immunological response and emerge from D. suzukii (Rossi Stacconi et al. 2015). The mechanism regulating the immune response to wasp parasitoid has been widely studied in D. melanogaster. Our results found parasitoid adults emerged from only 50-60\% of the exposed larvae of D. melanogaster, a finding that is consistent knowing that parasitism success varies considerably according to geographical population strains and genetics (Kraaijeveld and Godfray 1999). Indeed, recent work has demonstrated that D. suzukii has a higher hemocyte load than D. melanogaster, which makes it more resistant to several larval parasitoids (Kacsoh and Schlenke 2012; Poyet et al. 2013). Although no adults of L. heterotoma emerged in our laboratory tests, a higher mortality of $D$. suzukii larvae exposed to this parasitoid relative to control larvae was recorded, suggesting this species, even if unable to reach adulthood, may possess the capability to begin development and cause death of its host larvae, as reported by other authors (Chabert et al. 
2012). In L. boulardi, no mortality difference between exposed and non-exposed larvae was recorded.

Pachycrepoideus vindemiae was the main pupal parasitoid found during our field monitoring, as observed in France (Fleury et al. 2009). This parasitoid is reported to be one of the three most abundant frugivorous Drosophila parasitoids in South France (Chabert et al. 2012), and its presence has already been assessed in other Italian areas (Nøstvik 1954). Pachycrepoideus vindemiae was collected in all surveyed sites, but showed different population dynamics. Population trend differences between the localities might be influenced by the presence of alternative hosts. In fact, $P$. vindemiae is known to parasitize over 60 fly species, and was shown to dominate interspecific competition (Wang and Messing 2004; Rossi Stacconi et al. 2013). Higher numbers of this pupal parasitoid emerged from the fruit exposed for 14 days, in which higher numbers of pupae promoted the attraction of $P$. vindemiae. This species was also more attracted to banana traps as explained above for Leptopilina spp. (Chabert et al. 2012; Rossi Stacconi et al. 2013).

We chose not to test $P$. vindemiae in the laboratory because its capability to parasitize $D$. suzukii at a rate of about $60 \%$ (Chabert et al. 2012; Rossi Stacconi et al. 2015), similar to that recorded on $D$. melanogaster (Delpuech et al. 1994), is well established. Currently, $P$. vindemiae is one of the most widely studied potential biological control agents of $D$. suzukii. Nonetheless, its successful activity on D. suzukii is counter balanced by a high number of host species and its role as a hyperparasitoid (Baeza-Larios et al 2002; Guillén et al 2002).

Although T. cf. drosophilae is considered the other main widespread and global pupal parasitoid of drosophilids (Fleury et al. 2009; Asplen et al. 2015), fewer individuals of this species were recorded in our field survey and in another area of North Italy (Rossi Stacconi et al. 2015). Indeed, in Piedmont this pupal parasitoid was absent, while in Emilia Romagna and Lombardy, in spite of the few specimens recorded, it displayed similar population dynamics. Little information existed on this parasitoid (Romani et al. 2002; Romani et al. 2008; Small et al. 2012) until introduction of the exotic fly sparked interest. Currently, $T$. cf. drosophilae has proved it can successfully parasitize $D$. suzukii in previous laboratory research (Chabert et al. 2012; Gabarra et al. 2015). In our laboratory tests, the population of $T$. cf. drosophilae collected in Lombardy parasitized both $D$. suzukii and $D$. melanogaster with the same effectiveness. The longer development time of $T$. cf. drosophilae in D. suzukii as opposed to D. melanogaster, recorded in the no-choice experiment, may have been due to the larger D. suzukii pupae (resulting in more food available to parasitoid larvae), as shown in other host-parasitoid systems (Dindo and Grenier 2014). Furthermore, in choice experiments performed for the first time on this species, the parasitoid showed the same preference for pupae of both hosts. 
These results, together with its limited host range and the feasibility of its mass rearing, make $T$. cf. drosophilae a good candidate for augmentative biological control of $D$. suzukii.

Our results suggest the possibility of natural enemy-mediated apparent competition in communities of Drosophila spp. and their parasitoids. As a matter of fact, high numbers of indigenous Drosophilidae emerged in spite of the abundance of parasitoids. Consequently, the possibility that native parasitoids can effectively adapt to and control $D$. suzukii, also due to its higher resistance to some parasitoids, still remains limited. Moreover, although more efficient parasitoids were reported in the area of origin, a specific enemy of $D$. suzukii to release in a classical biological control program is yet to be identified. Therefore, further investigations on indigenous enemies, in particular on $T$. cf. drosophilae, that was revealed to be a promising biological control agent, should be carried out to achieve effective control of $D$. suzukii through their rearing and release in the field in augmentative biological control programs.

LT, MLD and DL conceived and designed research. FM, EM, NA, SF, and CJ conducted field surveys. FM and EM conducted laboratory tests. DS analysed data. FM and LT wrote the manuscript. All authors read and approved the manuscript.

\section{Acknowledgements}

We are grateful to Mattias Forshage (Station Linné, Färjestaden, Sweden), Augusto Loni (Dip. Scienze Agrarie, Agro-Alimentari ed Ambientali, University of Pisa, Italy) and David Notton (Natural History Museum, London, UK) for parasitoid identifications. We are also grateful to our colleagues at CReSO (Cuneo), Studio Pegaso (Torino), and DISAA (University of Milan) for their help with the field surveys. This research was supported by the project "Insects and globalisation: sustainable control of exotic species in agro-forestry ecosystems (GEISCA, PRIN 2010-11)”, financed by the Italian Ministry for Education, University and Research, and by a grant from Regione Piemonte - Assessorato Agricoltura.

\section{References}

Allemand R, Lemaitre C, Frey F, Boulétreau M, Vavre F, Nordlander G, Van Alphen J, Carton Y (2002) Phylogeny of six African Leptopilina species (Hymenoptera: Cynipoidea, Figitidae), parasitoids of Drosophila, with description of three new species. Ann Soc Entomol Fr 38(4):319-332

Asplen MK, Anfora G, Biondi A, Choi D-S, Chu D, Daane KM, Gibert P, Gutierrez AP, Hoelmer KA, Hutchison WD, Isaacs R, Jiang Z-L, Kárpáti Z, Kimura MT, Pascual M, Philips CR, 
Plantamp C, Ponti L, Vétek G, Vogt H, Walton VM, Yu Y, Zappalà L, Desneux N (2015) Invasion biology of spotted wing Drosophila (Drosophila suzukii): a global perspective and future priorities. J Pest Sci 88:469-494

Baeza-Larios G, Sivinski J, Oller T, Aluja M (2002) The ability of Coptera haywardi (Ogloblin) (Hymenoptera: Diapriidae) to locate and attack the pupae of the Mediterranean fruit fly, Ceratitis capitata (Wiedemann) (Diptera: Tephritidae), under seminatural conditions. Biol Control 23:213-218

Bouček Z (1963) A taxonomic study in Spalangia Latr. (Hymenoptera, Chalcidoidea). Acta Entomol Mus Nat Pragae 35:429-512

Bruck DJ, Bolda MP, Tanigoshi L, Klick J, Kleiber J, DeFrancesco J, Gerdeman B, Spitler H (2011) Laboratory and field comparisons of insecticides to reduce infestation of Drosophila suzukii in berry crops. Pest Manag Sci 67(11):1375-1385

Burrack H, Asplen M, Bahder L, Collins J, Drummond FA, Guédot C, Isaacs R, Johnson D, Blanton A, Lee JC, Loeb G, Rodriguez-Saona C, Van Timmeren S, Walsh D, McPhie DR (2015) Multistate comparison of attractants for monitoring Drosophila suzukii (Diptera: Drosophilidae) in blueberries and caneberries. Environ Entomol 44(3):704-712

Calabria G, Máca J, Bächli G, Serra L, Pascual M (2012) First records of the potential pest species Drosophila suzukii (Diptera: Drosophilidae) in Europe. J Appl Entomol 136(1-2):139-147

Campan E, Couty A, Carton Y, Pham-Delègue MH, Kaiser L (2002) Variability and genetic components of innate fruit odour recognition in a parasitoid of Drosophila. Physiol Entomol 27(3):243-250

Carton Y, Haouas S, Marrakchi M, Hochberg M (1991) Two competing parasitoid species coexist in sympatry. Oikos 60(2):222-230

Cha DH, Adams T, Rogg H, Landolt PJ (2012) Identification and field evaluation of fermentation volatiles from wine and vinegar that mediate attraction of Spotted Wing Drosophila, Drosophila suzukii. J Chem Ecol 38(11):1419-1431

Cha DH, Hesler SP, Cowles RS, Voght H, Loeb GM, Landolt PJ (2013) Comparison of a synthetic chemical lure and standard fermented baits for trapping Drosophila suzukii (Diptera:

Drosophilidae). Environ Entomol 42(5):1052-1060

Cha DH, Adams T, Werle CT, Sampson BJ, Adamczyk JJ, Rogg H, Landolt PJ (2014) A fourcomponent synthetic attractant for Drosophila suzukii (Diptera: Drosophilidae) isolated from fermented bait headspace. Pest Manag Sci 70(2):324-331 
Cha DH, Hesler SP, Park S, Adams TB, Zack RS Rogg H, Loeb GM, Landolt PJ (2015) Simpler is better: fewer non-target insects trapped with a four-component chemical lure vs. a chemically more complex food-type bait for Drosophila suzukii. Entomol Exp Appl 154(3): 251-260

Chabert S, Allemand R, Poyet M, Eslin P, Gibert P (2012) Ability of European parasitoids (Hymenoptera) to control a new invasive Asiatic pest, Drosophila suzukii. Biol Control $63: 40-47$

Cini A, Ioriatti C, Anfora G (2012) A review of the invasion of Drosophila suzukii in Europe and a draft research agenda for integrated pest management. B. Insectol 65(1):149-160

De Ros G, Anfora G, Grassi A, Ioriatti C (2013) The potential economic impact of Drosophila suzukii on small fruits production in Trentino (Italy). IOBC-WPRS Bull 91:317-321

Delpuech JM, Frey E, Carton Y (1994) Genetic and epigenetic variation in suitability of a Drosophila host to 3 parasitoid species. Can J Zool 72(11):1940-1944

Deprà M, Poppe JL, Schmitz HJ, De Toni DC, Valente VLS (2014) The first records of the invasive pest Drosophila suzukii in the South American continent. J Pest Sci 87(3):379-383

Dindo ML, Grenier S (2014) Production of Dipteran Parasitoids. In: Morales-Ramos JA, Rojas MG, Shapiro-Ilan DI, (eds) Mass Production of Beneficial Organisms: Invertebrates and Entomopathogens, Academic Press, London UK, pp 101-143

Escudero Colomar LA, Bosch D, Batllori L (2012) Drosophila suzukii, una nueva plaga de los frutales. Vida Rural 347:18-22

Ferreira LB, Tidon R (2005) Colonizing potential of Drosophilidae (Insecta, Diptera) in environments with different grades of urbanization. Biodivers Conserv 14(8): 1809-1821

Fleury F, Allemand R, Vavre F, Fouillet P, Boulétreau M (2000) Adaptive significance of a circadian clock: temporal segregation of activities reduces intrinsic competitive inferiority in Drosophila parasitoids. Proc Biol Sci 267(1447):1005-1010

Fleury F, Ris N, Allemand R, Fouillet P, Carton Y, Boulétreau M (2004) Ecological and genetic interactions in Drosophila-parasitoids communities: a case study with D. melanogaster, D. simulans and their common Leptopilina parasitoids in south-eastern France. Genetica 120(13):181-194

Fleury F, Gibert P, Ris N, Allemand R (2009) Ecology and life history evolution of frugivorous Drosophila parasitoids. In: Prevost G (ed) Advances in Parasitology-Parasitoids of Drosophila, $1^{\text {st }}$ ed. Amiens, France, pp 3-44

Forshage M, Norlander G (2008) Identification key to European genera of Eucoilinae (Hymenoptera, Cynipoidea, Figitidae). Insect Syst Evol 39(3):341-359 
Gabarra R, Riudavets J, Rodriguez GA, Pujade-Villar J, Arno J (2015) Prospects for the biological control of Drosophila suzukii. BioControl 60(3):331-339

Gargani E, Tarchi F, Frosinini R, Mazza G, Simoni S (2013) Notes on Drosophila suzukii Matsumura (Diptera Drosophilidae): field survey in Tuscany and laboratory evaluation of organic products. Redia 96:85-90

Goodhue RE, Bolda M, Farnsworth D, Williams JC, Zalom FG (2011) Spotted wing drosophila infestation of California strawberries and raspberries: Economic analysis of potential revenue losses and control costs. Pest Manag Sci 67(11):1396-1402

Graham MD de V (1969) The Pteromalidae of Northwestern Europe. Bull Brit Mus (NH), Suppl $16: 3-908$

Grassi A, Pallaoro M (2012) Drosophila suzukii (Matsumura), a revolution for soft fruits in Trentino. In: Foerdergemeinschaft Oekologischer Obstbau e.V. (FOEKO) (ed) Ecofruit: 15th International Conference on Organic Fruit-Growing. Hohenheim, Germany, 20-22 February 2012, pp 179-186

Guillén L, Aluja M, Equihua M, Sivinski J (2002) Performance of two fruit fly (Diptera: Tephritidae) pupal parasitoids (Coptera haywardi [Hymenoptera: Diapriidae] and Pachycrepoideus vindemiae [Hymenoptera: Pteromalidae]) under different environmental soil conditions Biol Control 23:219-227

Hauser M (2011) A historic account of the invasion of Drosophila suzukii (Matsumura) (Diptera: Drosophilidae) in the continental United States, with remarks on their identification. Pest Manag Sci (67):1352-1357

Iglesias LE, Nyoike TW, Liburd OE (2014) Effect of trap design, bait type, and age on captures of Drosophila suzukii (Diptera: Drosophilidae) in berry crops. J Econ Entomol 107(4): 15081518.

Janssen A, Driessen G, De Haan M, Roodbol N (1987) The impact of parasitoids on natural populations of temperate woodland Drosophila. J Neth Zool 38(1):61-73

Kacsoh BZ, Schlenke TA (2012) High hemocyte load is associated with increased resistance against parasitoids in Drosophila suzukii, a relative of D. melanogaster. PLOS ONE 7: e34721. doi: 10.1371/journal.pone.0034721

Kanzawa T (1939) Studies on Drosophila suzukii Mats. Rev. Appl. Ent. 29:622 [Abstract] Kasuya N, Mitsui H, Ideo S, Watada M, Kimura MT (2013) Ecological, morphological and molecular studies on Ganaspis individuals (Hymenoptera: Figitidae) attacking Drosophila suzukii (Diptera: Drosophilidae). Appl Entomol Zool 48(1):87-92 
Kinjo H, Kunimi Y, Ban T, Nakai M (2013) Oviposition efficacy of Drosophila suzukii (Diptera: Drosophilidae) on different cultivars of blueberry. J Econ Entomol 106(4):1767-1771

Kohyama TI, Kimura MT (2015) Toxicity of venom of Asobara and Leptopilina species to Drosophila species. Physiol Entomol doi: 10.1111/phen.12115

Kraaijeveld AR, Van Alphen JM (1994) Geographic variation in encapsulation ability of

Drosophila melanogaster larvae and evidence for parasitoid-specific. Evol Ecol 9(1):10-17

Kraaijeveld AR, Godfray HCJ (1999) Geographical patterns in the evolution of resistance and virulence in Drosophila and its parasitoids. Amer Nat 153(S5):S61-S74

Landolt PJ, Adams T, Rogg H (2012a) Trapping spotted wing drosophila, Drosophila suzukii (Matsumura) (Diptera: Drosophilidae), with combinations of vinegar and wine, and acetic acid and ethanol. J Appl Entomol 136(1-2):148-154.

Landolt PJ, Adams T, Davis TS, Rogg H (2012b) Spotted wing drosophila, Drosophila suzukii (Diptera: Drosophilidae), trapped with combination of wines and vinegars. Fla Entomol 95(2):326-332

Marchiori CH, Arantes SB, Pereira LA, Silva Filho OM, Borges VR (2015) First record of Leptopilina boulardi Barbotin et al. (Hymenoptera: Figitidae: Eucoilinae) parasitizing of Zaprionus indianus gupta (Diptera: drosophilidae) in Brazil. Ciências Agrárias 24(2):321-324 Markow TA, O'Grady PM (2006) Collecting Drosophila in the wild. In: Elsevier (ed) Drosophila. A guide to species identification and use, Academic Press, London, pp 145-153

Mazzetto F, Pansa MG, Ingegno BL, Tavella L, Alma A (2015) Monitoring of the exotic fly Drosophila suzukii in stone, pome and soft fruit orchards in NW Italy. J Asia Pac Entomol $18(2): 321-329$

Mitsui H, Kimura MT (2010) Distribution, abundance and host association of two parasitoid species attacking frugivorous drosophilid larvae in central Japan. Eur J Entomol 107(4):535-540.

Mitsui H, Van Acterberg K, Nordlander G, Kimura MT (2007) Geographical distributions and host associations of larval parasitoids of frugivorous Drosophilidae in Japan. J Nat Hist 41(25):1731-1738.

Mitsui H, Beppu K, Kimura MT (2010) Seasonal life cycles and resource uses of flower- and fruitfeeding drosophilid flies (Diptera: Drosophilidae) in central Japan. Entomol Sci 13(1):60-67

Moiroux J, Delava E, Fleury F, Van Baaren J (2013) Local adaptation of a Drosophila parasitoid: habitat-specific differences in thermal reaction norms. J Evol Biol 26(5):1108-1116

Montchamp-Moreau C (1983) Interspecific competition between Drosophila melanogaster and Drosophila simulans: temperature effect on competitive ability and fitness components. Genet Sel Evol 15(3):367-378 
Nomano FY, Mitsui H, Kimura MT (2015) Capacity of Japanese Asobara species (Hymenoptera: Braconidae) to parasitize a fruit pest Drosophila suzukii (Diptera: Drosophilidae). J Appl Entomol 139(1-2): 105-113

Nøstvik E (1954) Biological studies of Pachycrepoideus dubius Ashmead (Chalcidoidea:

Pteromalidae), a pupal parasite of various Diptera. Oikos 5(2):195-204

Novković B, Oikawa A, Murata Y, Mitsui H, Kimura MT (2012) Abundance and host association of parasitoids attacking frugivorous drosophilids in Iriomote-jima, a subtropical island of Japan. Eur J Entomol 109(4):517- 526

Poyet M, Havard S, Prevost G, Chabrerie O, Doury G, Gibert P, Eslin P (2013) Resistance of Drosophila suzukii to the larval parasitoids Leptopilina heterotoma and Asobara japonica is related to haemocyte load. Physiol Entomol 38(1):45-53

Poyet M, Eslin P, Héraude M, Le Roux V, Prévost G, Gibert P, Chabrerie O (2014) Invasive host for invasive pest: when the Asiatic cherry fly (Drosophila suzukii) meets the American black cherry (Prunus serotina) in Europe. Agr Forest Entomol 16(3):251-259

Romani R, Isidoro N, Bin F, Vinson SB (2002) Host recognition in the pupal parasitoid Trichopria drosophilae: a morpho-functional approach. Entomol Exp Appl 105(2/3):119-128

Romani R, Rosi MC, Isidoro N, Bin F (2008) The role of the antennae during courtship behaviour in the parasitic wasp Trichopria drosophilae. J Exp Biol 211(15):2486-2491

Rossi Stacconi MV, Grassi A, Dalton DT, Miller B, Ouantar M, Loni A, Ioriatti C, Walton VM, Anfora G (2013) First field records of Pachycrepoideus vindemiae as a parasitoid of Drosophila suzukii in European and Oregon small fruit production areas. Entomologia $1(1): 11-16$

Rossi Stacconi MV, Buffington M, Daane KM, Dalton DT, Grassi A, Kaçar G, Miller B, Miller JC, Baser N, Ioriatti C, Walton VM, Wilman NG, Wang X, Anfora G (2015) Host stage preference, efficacy and fecundity of parasitoids attacking Drosophila suzukii in newly invaded areas. Biol Control 84:28-35

Rota Stabelli O, Blaxter M, Anfora G (2013) Drosophila suzukii. Curr Biol 23(1):R8-R9 Small C, Paddibhatla I, Rajwani R, Govind S (2012) An introduction to parasitic wasps of Drosophila and the antiparasite immune response. J Vis Exp 63. doi: 10.3791/3347

Van Alphen JJM, Thunissenn I (1993) Host selection and sex allocation by Pachycrepoideus vindemiae Rondani (Pteromalidae) as a facultative hyperparasitoid of Asobara tabida Nees (Braconidae; Alysiinae) and Leptopilina heterotoma (Cynipoidea; Eucoilidae). Neth J Zool 33(4):497-514 
Vet LEM, Van Opzeeland K (1985) Olfactory microhabitat selection in Leptopilina heterotoma (Thomson) (Hym.: Eucoilidae), a parasitoid of Drosophilidae. J Neth Zool 35(3):497-504 Vlach J (2010) Identifying Drosophila suzukii. Oregon Department of Agriculture.

http://www.ipm.ucdavis.edu/PDF/PMG/SWD-ID-Dsuzukii.pdf. Accessed 20 October 2015 Wang X-G, Messing RH (2004) The ectoparasitic pupal parasitoid, Pachycrepoideus vindemmiae (Hymenoptera: Pteromalidae), attacks other primary tephritid fruit fly parasitoids: host expansion and potential non-target impact. Biol Control 31:227-236

Weydert C, Mandrin J-F, Bourgouin B (2012) Le ravageur Drosophila suzukii. Point sur la situation en arboriculture fruitière et petit fruits. InfosCTIFL 279:45-52

Yu D, Zalom FG, Hamby KA (2013) Host status and fruit odor response of Drosophila suzukii (Diptera: Drosophilidae) to figs and mulberries. J Econ Entomol 106:1932-1937 
Table 1 - Locations and characteristics of the sites where field surveys were carried out in 2014

\begin{tabular}{|c|c|c|c|}
\hline Region & Site & Position & Crop/vegetation \\
\hline \multirow[t]{3}{*}{ Piedmont } & Boves & $44^{\circ} 20^{\prime} 54^{\prime \prime} \mathrm{N} 7^{\circ} 32^{\prime} 04^{\prime \prime} \mathrm{E} 548 \mathrm{~m}$ a.l.s. & Blueberry \\
\hline & Paesana & $44^{\circ} 40^{\prime} 47^{\prime \prime} \mathrm{N} 7^{\circ} 17^{\prime} 21^{\prime \prime} \mathrm{E} 572 \mathrm{~m}$ a.1.s. & Blueberry \\
\hline & Peveragno & $44^{\circ} 19^{\prime} 23^{\prime \prime} \mathrm{N} 7^{\circ} 37^{\prime} 45^{\prime \prime} \mathrm{E} 590 \mathrm{~m}$ a.l.s & Raspberry \\
\hline \multirow[t]{3}{*}{ Lombardy } & Arcagna & $45^{\circ} 20^{\prime} 17^{\prime \prime} \mathrm{N} 9^{\circ} 27^{\prime} 07^{\prime \prime} \mathrm{E} 79 \mathrm{~m}$ a.l.s. & Raspberry \\
\hline & Minoprio 1 & 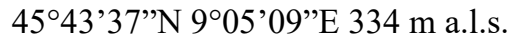 & Raspberry \\
\hline & Minoprio 2 & $45^{\circ} 43^{\prime} 39^{\prime \prime} \mathrm{N} 9^{\circ} 05^{\prime} 12^{\prime \prime} \mathrm{E} 334 \mathrm{~m}$ a.l.s. & Blueberry \\
\hline Emilia & Bologna & $44^{\circ} 32^{\prime} 57^{\prime} \mathrm{N} 11^{\circ} 23^{\prime} 15^{\prime \prime} \mathrm{E} 54 \mathrm{~m}$ a.l.s. & Fruit trees and bushes \\
\hline \multirow[t]{2}{*}{ Romagna } & Cadriano & $44^{\circ} 32^{\prime} 57^{\prime} ’ \mathrm{~N} 11^{\circ} 23^{\prime} 15^{\prime \prime} \mathrm{E} 28 \mathrm{~m}$ a.l.s & Cherries \\
\hline & Dodici Morelli & $44^{\circ} 48^{\prime} 24^{\prime \prime} \mathrm{N} 11^{\circ} 17^{\prime} 07^{\prime \prime} \mathrm{E} 15 \mathrm{~m}$ a.l.s. & Mulberries in uncultivated area \\
\hline
\end{tabular}


Table 2 - Total numbers of Drosophila spp. and \% of Drosophila suzukii collected by apple cider vinegar (ACV) traps and emerged from fruit dishes, and total numbers of parasitoids emerged from fruit dishes exposed in the field in 2014

\begin{tabular}{|c|c|c|c|c|c|c|c|c|c|c|c|}
\hline \multirow[t]{2}{*}{ Sites } & \multirow{2}{*}{$\begin{array}{l}\text { Time } \\
\text { exposure }\end{array}$} & \multicolumn{2}{|l|}{ ACV traps } & \multicolumn{2}{|l|}{ Fruit dish } & \multicolumn{6}{|c|}{ Parasitoids (no.) } \\
\hline & & $\begin{array}{l}\text { Drosophilidae } \\
\text { (no.) }\end{array}$ & $\begin{array}{l}\text { D. suzukii } \\
(\%)\end{array}$ & $\begin{array}{l}\text { Drosophilidae } \\
\text { (no.) }\end{array}$ & $\begin{array}{l}\text { D. suzukii } \\
(\%)\end{array}$ & $\begin{array}{l}\text { L. } \\
\text { boulardi }\end{array}$ & $\begin{array}{l}\text { L. } \\
\text { heterotoma }\end{array}$ & $\begin{array}{l}P . \\
\text { vindemiae }\end{array}$ & $\begin{array}{l}\text { T. cf. } \\
\text { drosophilae }\end{array}$ & $\begin{array}{l}\text { A. } \\
\text { tabida }\end{array}$ & $\begin{array}{l}\text { S. } \\
\text { erythromera }\end{array}$ \\
\hline \multirow[t]{2}{*}{ Boves } & 7 & 1,619 & 55.3 & 12,790 & 0.70 & 251 & 10 & 4 & 0 & 0 & 0 \\
\hline & 14 & & & 3,203 & 1.25 & 99 & 50 & 142 & 0 & 0 & 0 \\
\hline \multirow[t]{2}{*}{ Paesana } & 7 & 5,679 & 34.9 & 15,753 & 1.94 & 495 & 482 & 19 & 0 & 1 & 0 \\
\hline & 14 & & & 3,832 & 2.61 & 401 & 196 & 453 & 0 & 0 & 21 \\
\hline \multirow[t]{2}{*}{ Peveragno } & 7 & 1,132 & 71.9 & 15,328 & 2.23 & 1,048 & 2,001 & 41 & 0 & 4 & 0 \\
\hline & 14 & & & 3,898 & 1.23 & 359 & 372 & 35 & 0 & 0 & 2 \\
\hline \multirow[t]{2}{*}{ Arcagna } & 7 & 709 & 76.9 & 9,808 & 0.10 & 725 & 7 & 107 & 33 & 22 & 0 \\
\hline & 14 & & & 462 & 4.11 & 211 & 8 & 1,133 & 25 & 40 & 0 \\
\hline \multirow[t]{2}{*}{ Minoprio 1} & 7 & 5,907 & 86.9 & 6,684 & 1.35 & 438 & 72 & 119 & 43 & 3 & 1 \\
\hline & 14 & & & 1,744 & 0.52 & 163 & 87 & 228 & 10 & 11 & 3 \\
\hline \multirow[t]{2}{*}{ Minoprio 2} & 7 & 4,459 & 81.2 & 3,365 & 2.08 & 393 & 9 & 20 & 2 & 0 & 3 \\
\hline & 14 & & & 920 & 0.33 & 110 & 2 & 27 & 16 & 0 & 0 \\
\hline \multirow[t]{2}{*}{ Bologna } & 7 & 3,780 & 22.3 & 2,158 & 0.00 & 343 & 0 & 29 & 14 & 0 & 0 \\
\hline & 14 & & & 180 & 0.56 & 12 & 0 & 113 & 4 & 0 & 0 \\
\hline \multirow[t]{2}{*}{ Cadriano } & 7 & 1,415 & 55.2 & 1,627 & 1.17 & 130 & 0 & 8 & 13 & 0 & 0 \\
\hline & 14 & & & 185 & 0.00 & 5 & 0 & 31 & 0 & 0 & 0 \\
\hline \multirow[t]{2}{*}{ Dodici Morelli } & 7 & 3,672 & 56.6 & 1,848 & 0.49 & 368 & 0 & 73 & 26 & 0 & 0 \\
\hline & 14 & & & 132 & 0.76 & 54 & 0 & 185 & 2 & 0 & 0 \\
\hline
\end{tabular}


Table 3 - Mean number of emerged parasitoid adults pooled over the season for Locality, Fruit, and Exposure and their interactions

\begin{tabular}{|c|c|c|c|c|c|c|c|c|c|c|}
\hline \multirow[t]{2}{*}{ Parasitoid } & \multirow[t]{2}{*}{ Locality } & \multicolumn{2}{|c|}{7 day exposure } & \multicolumn{2}{|c|}{14 day exposure } & \multicolumn{2}{|l|}{ Fruits } & \multicolumn{2}{|c|}{ Interval of exposure } & \multirow[t]{2}{*}{ Total } \\
\hline & & Banana & Blueberry & Banana & Blueberry & Banana & Blueberry & 7 days & 14 days & \\
\hline \multirow[t]{4}{*}{ L. boulardi } & Emilia Romagna & $6.89 \pm 11.28$ & $0.15 \pm 1.18$ & $0.89 \pm 3.23$ & $0.10 \pm 0.38$ & $3.89 \mathrm{a}$ & $0.13 \mathrm{~b}$ & $3.52 \mathrm{a}$ & $0.50 \mathrm{~b}$ & 2.01 \\
\hline & Lombardy & $5.15 \pm 12.94$ & $3.36 \pm 9.44$ & $3.32 \pm 7.75$ & $3.40 \pm 5.82$ & 4.24 & 3.38 & 4.26 & 3.36 & 3.81 \\
\hline & Piedmont & $9.17 \pm 23.22$ & $8.82 \pm 17.14$ & $2.96 \pm 7.45$ & $8.97 \pm 22.27$ & 6.07 & 8.90 & 9.00 & 5.97 & 7.48 \\
\hline & Total & $7.07 \mathrm{a}$ & $4.11 \mathrm{~b}$ & 2.39 & 4.16 & $4.73 a$ & $4.14 b$ & $5.59 \mathrm{a}$ & $3.28 b$ & 4.43 \\
\hline \multirow[t]{4}{*}{ L. heterotoma } & Emilia Romagna & $0.00 \pm 0.00$ & $0.00 \pm 0.00$ & $0.00 \pm 0.00$ & $0.00 \pm 0.00$ & 0.00 & 0.00 & 0.00 & 0.00 & 0.00 \\
\hline & Lombardy & $0.54 \pm 1.93$ & $0.04 \pm 0.20$ & $0.88 \pm 4.30$ & $0.47 \pm 1.74$ & 0.71 & 0.26 & 0.29 & 0.68 & 0.48 \\
\hline & Piedmont & $14.75 \pm 40.38$ & $3.65 \pm 9.62$ & $5.01 \pm 13.98$ & $3.57 \pm 10.60$ & 9.88 & 3.61 & 9.20 & 4.29 & 6.75 \\
\hline & Total & $5.10 \mathrm{a}$ & $1.23 \mathrm{~b}$ & 1.96 & 1.35 & 3.53 & 1.29 & 3.16 & 1.66 & 2.41 \\
\hline \multirow[t]{4}{*}{ P. vindemiae } & Emilia Romagna & $0.81 \pm 2.49$ & $0.00 \pm 0.00$ & $3.93 \pm 9.56$ & $0.64 \pm 3.48$ & 2.37 & 0.32 & $0.41 b$ & $2.29 \mathrm{a}$ & 1.35 \\
\hline & Lombardy & $2.07 \pm 8.57$ & $0.29 \pm 0.97$ & $18.38 \pm 40.75$ & $0.90 \pm 2.66$ & 10.23 & 0.60 & $1.18 b$ & $9.64 a$ & 5.41 \\
\hline & Piedmont & $0.18 \pm 1.19$ & $0.03 \pm 0.17$ & $8.67 \pm 34.57$ & $0.08 \pm 0.44$ & 4.43 & 0.06 & $0.11 b$ & $4.38 \mathrm{a}$ & 2.24 \\
\hline & Total & $1.02 \mathrm{a}$ & $0.11 \mathrm{~b}$ & $10.33 a$ & $0.54 b$ & $5.67 \mathrm{a}$ & $0.32 b$ & $0.56 b$ & $5.43 a$ & 3.00 \\
\hline \multirow[t]{4}{*}{ T. cf. drosophilae } & Emilia Romagna & $0.11 \pm 0.72$ & $0.00 \pm 0.00$ & $0.00 \pm 0.00$ & $0.08 \pm 0.37$ & 0.06 & 0.04 & 0.06 & 0.04 & 0.05 \\
\hline & Lombardy & $0.06 \pm 0.37$ & $0.53 \pm 1.63$ & $0.21 \pm 0.67$ & $0.50 \pm 2.02$ & 0.14 & 0.52 & 0.30 & 0.36 & 0.33 \\
\hline & Piedmont & $0.00 \pm 0.00$ & $0.00 \pm 0.00$ & $0.00 \pm 0.00$ & $0.00 \pm 0.00$ & 0.00 & 0.00 & 0.00 & 0.00 & 0.00 \\
\hline & Total & 0.06 & 0.18 & 0.07 & 0.19 & 0.06 & 0.19 & 0.12 & 0.13 & 0.12 \\
\hline
\end{tabular}

SD was added only to three-way interaction. Data are referred to Dataset 7-14 days. When significant, mean values were separated through

sequential Bonferroni post hoc test (different letters indicate significant difference between the compared treatments within row). In Locality*Fruit and Exposure*Fruit interactions, means referred to Fruits were separated in each level of Locality or Exposure, respectively. In Locality*Exposure interaction, means referred to Exposure were separated in each level of Locality 
Table 4 - Statistical significance of the different fixed and random effects referred to Dataset 7-14 days obtained applying a Generalized linear mixed effect model procedure with a Poisson distribution and $\log$ link

\begin{tabular}{lllll}
\hline Factors & \multicolumn{2}{l}{ Significance } & & \\
\cline { 2 - 5 } & L. boulardi & L.heterotoma & P. vindemiae & T. cf. drosophilae \\
\hline Fixed effects & & & & \\
Locality & $\mathrm{ns}$ & $\mathrm{ns}$ & $\mathrm{ns}$ & $\mathrm{ns}$ \\
Fruit & 0.005 & $\mathrm{~ns}$ & $<0.001$ & $\mathrm{~ns}$ \\
Exposure & 0.002 & $\mathrm{~ns}$ & $<0.001$ & $\mathrm{~ns}$ \\
Locality*Fruit & $<0.001$ & $\mathrm{~ns}$ & $\mathrm{~ns}$ & $\mathrm{~ns}$ \\
Locality*Exposure & 0.007 & $\mathrm{~ns}$ & 0.007 & $\mathrm{~ns}$ \\
Exposure*Fruit & $<0.001$ & $<0.001$ & 0.047 & $\mathrm{~ns}$ \\
Random effects & & & & \\
Site (Locality) & $\mathrm{ns}$ & $\mathrm{ns}$ & $\mathrm{ns}$ & $\mathrm{ns}$ \\
Block (Site) & 0.038 & $\mathrm{~ns}$ & 0.043 & $\mathrm{~ns}$ \\
Fruit*Site (Locality) & $\mathrm{ns}$ & $\mathrm{ns}$ & $\mathrm{ns}$ & $\mathrm{ns}$ \\
Exposure*Site (Locality) & $\mathrm{ns}$ & $\mathrm{ns}$ & $\mathrm{ns}$ & $<0.001$ \\
\hline
\end{tabular}

Mean effects are reported in Table 3 
Table 5 - Mean number of emerged parasitoid adults pooled over the season for Locality, Fruit and their interaction

\begin{tabular}{|c|c|c|c|c|}
\hline \multirow[t]{2}{*}{ Parasitoid } & \multirow[t]{2}{*}{ Locality } & \multicolumn{2}{|l|}{ Fruits } & \multirow[t]{2}{*}{ Total } \\
\hline & & Banana & Blueberry & \\
\hline \multirow[t]{4}{*}{ L. boulardi } & Emilia Romagna & $5.72 \pm 10.91 \mathrm{a}$ & $0.12 \pm 0.93 b$ & 2.92 \\
\hline & Lombardy & $5.95 \pm 15.77$ & $4.84 \pm 14.76$ & 5.40 \\
\hline & Piedmont & $6.22 \pm 17.45$ & $6.24 \pm 13.78$ & 6.23 \\
\hline & Total & $5.96 \mathrm{a}$ & $3.73 b$ & 4.85 \\
\hline \multirow[t]{4}{*}{ L. heterotoma } & Emilia Romagna & $0.00 \pm 0.00$ & $0.00 \pm 0.00$ & 0.00 \\
\hline & Lombardy & $0.50 \pm 1.94$ & $0.10 \pm 0.55$ & 0.30 \\
\hline & Piedmont & $12.35 \pm 37.39$ & $4.97 \pm 15.69$ & 8.66 \\
\hline & Total & 4.28 & 1.69 & 2.99 \\
\hline \multirow[t]{4}{*}{ P. vindemiae } & Emilia Romagna & $0.76 \pm 3.15$ & $0.00 \pm 0.00$ & 0.38 \\
\hline & Lombardy & $1.47 \pm 6.41$ & $0.21 \pm 0.75$ & 0.84 \\
\hline & Piedmont & $0.37 \pm 2.92$ & $0.08 \pm 0.68$ & 0.23 \\
\hline & Total & 0.87 & 0.10 & 0.49 \\
\hline \multirow[t]{4}{*}{ T. cf. drosophilae } & Emilia Romagna & $0.25 \pm 1.19 \mathrm{a}$ & $0.12 \pm 0.57 \mathrm{~b}$ & 0.19 \\
\hline & Lombardy & $0.19 \pm 1.18$ & $0.35 \pm 1.22$ & 0.27 \\
\hline & Piedmont & $0.00 \pm 0.00$ & $0.00 \pm 0.00$ & 0.00 \\
\hline & Total & 0.15 & 0.16 & 0.16 \\
\hline
\end{tabular}

SD was added only to three-way interaction. Data are referred to Dataset 7 days. When significant, mean values were separated through sequential Bonferroni post hoc test (different letters indicate significant difference between the compared treatments within row). In Locality*Fruit interaction, means referred to Fruits were separated in each level of Locality 
Table 6 - Statistical significance of the different fixed and random effects referred to Dataset 7 days obtained applying a Generalized linear mixed effect model procedure with a Poisson distribution and log link

\begin{tabular}{lllll}
\hline Factors & Significance & & & \\
\cline { 2 - 5 } & L. boulardi & L. heterotoma & P. vindemiae & T. cf. drosophilae \\
\hline Fixed effects & $\mathrm{ns}$ & $\mathrm{ns}$ & $\mathrm{ns}$ & $\mathrm{ns}$ \\
Locality & 0.027 & $\mathrm{~ns}$ & $\mathrm{~ns}$ & $\mathrm{~ns}$ \\
Fruits & 0.003 & $\mathrm{~ns}$ & $\mathrm{~ns}$ & 0.044 \\
Locality*Fruits & & & & \\
Random effects & $\mathrm{ns}$ & $\mathrm{ns}$ & $\mathrm{ns}$ & $\mathrm{ns}$ \\
Site (Locality) & 0.038 & $\mathrm{~ns}$ & $\mathrm{~ns}$ & $\mathrm{~ns}$ \\
Block (Site) & $\mathrm{ns}$ & $\mathrm{ns}$ & $\mathrm{ns}$ & $\mathrm{ns}$ \\
Fruits*Site (Locality) & & & \\
\hline
\end{tabular}

Mean effects are reported in Table 5 
Table 7 - Mean number of emerged parasitoids and of dead host individuals in the laboratory tests

\begin{tabular}{|c|c|c|c|c|c|c|c|}
\hline \multirow[t]{2}{*}{ Test } & \multirow[t]{2}{*}{ Species } & \multirow[t]{2}{*}{ treatment (no. of replicates) } & \multicolumn{2}{|c|}{ Emerged parasitoids } & \multicolumn{2}{|c|}{ Dead individuals } & \multirow[t]{2}{*}{ Mean dead flies } \\
\hline & & & D. $m$. & D. $s$. & D. $m$. & D. $s$. & \\
\hline \multirow{9}{*}{$\begin{array}{l}\text { No } \\
\text { choice }\end{array}$} & \multirow[t]{3}{*}{ L. boulardi } & With parasitoid (15) & $5.33 \pm 2.82 \mathrm{a}$ & $0.00 \pm 0.00 \mathrm{~b}$ & $3.33 \pm 2.79$ & $1.73 \pm 1.49$ & 2.53 \\
\hline & & Control larvae (10) & & & $2.90 \pm 1.45$ & $1.40 \pm 1.26$ & 2.15 \\
\hline & & Mean dead & & & $3.12 \mathrm{a}$ & $1.57 \mathrm{~b}$ & \\
\hline & \multirow[t]{3}{*}{ L. heterotoma } & With parasitoid (8) & $6.13 \pm 4.12 \mathrm{a}$ & $0.00 \pm 0.00 \mathrm{~b}$ & $2.50 \pm 2.39 \mathrm{ab}$ & $4.00 \pm 2.07 \mathrm{a}$ & $3.25 \mathrm{a}$ \\
\hline & & Control larvae (10) & & & $2.90 \pm 1.45 \mathrm{ab}$ & $1.40 \pm 1.26 \mathrm{~b}$ & $2.15 \mathrm{~b}$ \\
\hline & & Mean dead & & & 2.70 & 2.70 & \\
\hline & \multirow[t]{3}{*}{ T. cf. drosophilae } & With parasitoid (6) & $7.67 \pm 1.03$ & $9.00 \pm 1.26$ & $2.33 \pm 1.03$ & $0.83 \pm 0.98$ & $1.58 \mathrm{a}$ \\
\hline & & Control pupae (6) & & & $0.83 \pm 0.75$ & $0.33 \pm 0.52$ & $0.58 \mathrm{~b}$ \\
\hline & & Mean dead & & & $1.58 \mathrm{a}$ & $0.58 \mathrm{~b}$ & \\
\hline Choice & T. cf. drosophilae & $(12)$ & $3.50 \pm 1.00$ & $4.50 \pm 1.00$ & $1.33 \pm 0.89 \mathrm{a}$ & $0.42 \pm 0.90 \mathrm{~b}$ & \\
\hline
\end{tabular}

SD was added to Emerged parasitoids or in the case of Dead individuals only to two-way interaction. Data were analyzed thorough Generalized linear model with a binomial distribution and a logit link. When significant, mean values were separated through Bonferroni post hoc test (different letters indicate significant difference between the compared treatments). In host*presence/absence of parasitoid interaction, all levels were compared 

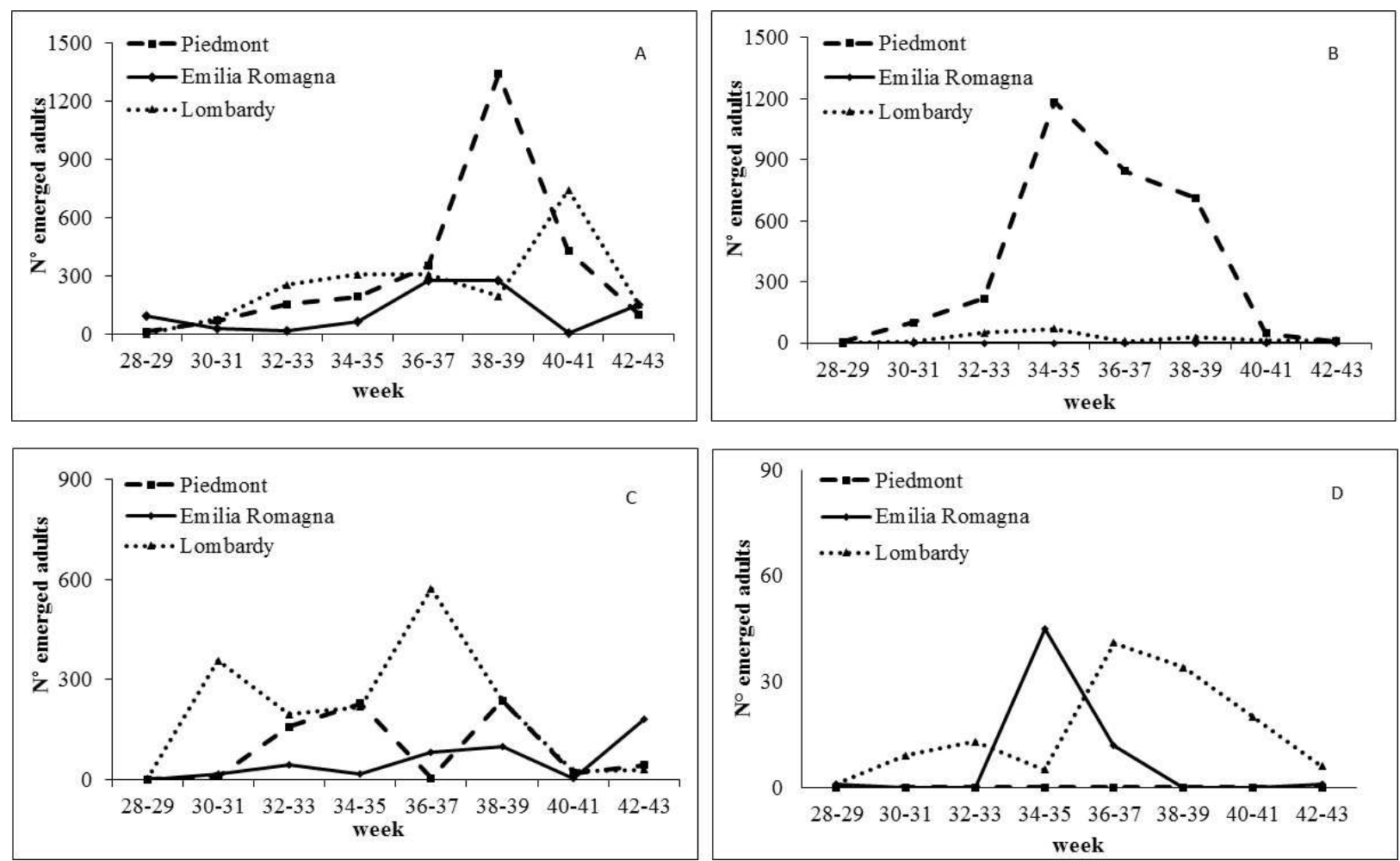

Figure 1 - Total numbers of Leptopilina boulardi (A), Leptopilina heterotoma (B),

Pachycrepoideus vindemiae (C) and Trichopria cf. drosophilae (D) emerged from banana and blueberries exposed in the field in Piedmont, Lombardy and Emilia Romagna during 2014 